\title{
Unidades fraseológicas em textos autênticos em francês: o exemplo dos contos infanto-juvenis
}

\section{Phraseological units in authentic texts in French: the example of the children's literature}

\author{
Ângelo de Souza Sampaio* \\ Universidade Federal da Babia \\ Salvador, Bahia, Brasil \\ Silvana Soares Costa Ribeiro** \\ Universidade Federal da Babia \\ Salvador, Bahia, Brasil
}

\begin{abstract}
Resumo: Este trabalho tem como base teórica os estudos recentes sobre fraseologia (GONZÁLEZ REY, 2015; GROSS, 1996; MEJRI, 1997, 2017; MONTEIRO-PLANTIN, 2014, 2017) e visa identificar e catalogar quantitativamente os fraseologismos presentes na série de contos infanto-juvenis Le Petit Nicolas (GOSCINNY; SEMPÉ, 1960-1964), estabelecendo regras de descrição e estrutura de codificação dos dados. Objetiva-se analisar as estruturas morfossintáticas, verificar a recorrência dos fraseologismos encontrados nos dez primeiros contos do volume 1 e averiguar quais expressões causam maior ou menor dificuldade de compreensão para um leitor brasileiro de francês. Os resultados apontam que as estruturas sintáticas dos fraseologismos em francês são próximas às do português, o que não aumenta a complexidade de compreensão.
\end{abstract}

Palavras-chave: Fraseologia. Estrutura sintática. Materiais autênticos. Le Petit Nicolas.

\begin{abstract}
This paper is based on the recent studies on phraseology (GONZÁLEZ REY, 2015; GROSS, 1996; MEJRI, 1997, 2017; MONTEIRO-PLANTIN, 2014, 2017) and aims to identify and catalog quantitatively the phraseologies present in the series of children's literature Le Petit Nicolas (GOSCINNY; SEMPÉ, 1960-1964) establishing rules of description and data coding structure. The aim is to analyze the morphosyntactic structures, to verify the recurrence of the phraseologies found in the first ten stories of volume 1 and to find out which expressions cause more or less difficulty of comprehension for a Brazilian reader of French. The results show that the syntactic structures of French phraseologies are close to Portuguese, which does not increase the complexity of comprehension.
\end{abstract}

Keywords: Phraseology. Syntactic structure. Authentic materials. Le Petit Nicolas.

\section{INTRODUÇÃO}

Em linguística, ao se referir às diferenças de ordem fônica, morfossintática ou mesmo semântico-lexical, sejam elas intra- ou interlínguas, dois termos são comumente

\footnotetext{
*Doutorando do Programa de Pós-Graduação em Língua e Cultura - PPGLinC - Universidade Federal da Babia, Salvador, Bahia, Brasil. E-mail: angelosampaio84@gmail.com.

** Professora do Programa de Pós-Graduação em Língua e Cultura - PPGLinC - Universidade Federal da Babia, Salvador, Bahia, Brasil. E-mail: silvanar@ufba.br.
} 
empregados: variação e mudança. O primeiro, segundo o Dicionário de linguística de Jean Dubois et al., é definido como

o fenômeno no qual, na prática corrente, uma língua determinada não é jamais, numa época, num lugar e num grupo social dados, idêntica ao que ela é noutra época, em outro lugar e em outro grupo social. A variação diacrônica da língua dá lugar aos diversos trabalhos de gramática histórica; a variação no espaço fornece seu objeto à geografia linguística e à dialetologia no sentido corrente do termo; a sociolinguística se ocupa da variação social. (DUBOIS et al., 2014, p. 568, grifos dos autores)

Observa-se que variação remete às inúmeras formas de uso de uma determinada língua, que competem entre si, variando de acordo com o espaço, temporal ou geográfico (variações diacrônica e diatópica), e de acordo com seus utentes, os falantes da língua (variações diafásica, diastrática e diagenérica) (cf. CHAMBERS; TRUDGILL, 1994; FERREIRA; CARDOSO, 1994; LEITE; CALLOU, 2006; CARDOSO, 2010; entre outros).

O termo mudança, por sua vez, é classificado como "o caráter mais importante da linguagem" (DUBOIS et al., 2014, p. 392). O autor explica que "em duas épocas dadas, constata-se que uma palavra, ou uma parte de palavra, ou processo morfológico, não se apresentam da mesma forma" (DUBOIS et al., 2014, p. 392-393). Assim, nota-se que, ao contrário do uso atribuído à variação, o termo mudança reporta-se às diferenças linguísticas já consolidadas, entre épocas. Tais diferenças caracterizam-se em transformações na língua e, por isso, geram mudanças.

Nesse sentido, ao considerarmos os estudos desenvolvidos por André Martinet (1978), que, a partir das dicotomias saussurianas (SAUSSURE, 1975), explica o funcionamento linguístico humano por intermédio do que foi denominado por ele como a Dupla Articulação da Linguagem, podemos presumir que a diversidade linguística de cunho morfológico está ligada à Primeira Articulação, enquanto que a diversidade fônica está relacionada à Segunda Articulação. Para melhor compreender tal associação, é preciso saber que

[...] pela PRIMEIRA ARTICULAÇÃO da linguagem, as experiências a transmitir, as necessidades que se pretende revelar a outrem, analisam-se numa série de unidades, cada uma delas possuidora de uma forma vocal e de um sentido. [...] Não podemos analisá-las em unidades sucessivas mais pequenas (sic) dotadas de sentido: é o conjunto cabeça que significa "cabeça", e não a soma de eventuais sentidos de cada um dos segmentos em que podemos dividi-lo - ca-, -be- e -ça, por exemplo. Mas a forma vocal é analisada numa sucessão de unidades, que contribuem todas para distinguir cabeça de outras unidades, como cabaça e cabeço. A isso chamamos a SEGUNDA ARTICULAÇÃO da linguagem. No caso de cabeça, há seis unidades desse tipo, que podemos representar pelas letras (sic) $\mathrm{k} \alpha \mathrm{b}$ e s a, convencionalmente colocadas entre barras oblíquas: /k $\alpha$ ’besa/. (MARTINET, 1978, p. 10 -12, grifos do autor)

Em outras palavras, a Primeira Articulação classifica as menores unidades portadoras de sentido de uma língua, os morfemas, ao passo que a Segunda Articulação divide os morfemas em unidades ainda menores, os fonemas, mesmo que estes não possuam, isoladamente, nenhum valor semântico. 
Contudo a teoria da Dupla Articulação da Linguagem deixa de lado a diversidade de cunho semântico-lexical, sobretudo no que tange às expressões ditas idiomáticas, construídas a partir da combinação das unidades lexicais da Primeira Articulação da Linguagem, presente nas línguas naturais. Tais expressões foram, durante muito tempo, marginalizadas pelos estudos linguísticos e pelo tratamento lexicográfico (MEJRI, 1997, 2017; MONTEIRO-PLANTIN, 2014), muito embora

as expressões idiomáticas ${ }^{1}$ sejam o puro produto da dinâmica das línguas vivas. Elas são a marca dos diferentes usos dos falantes ao longo dos tempos, o lugar da memória das comunidades linguísticas, o assento das diferentes configurações que os conceitos podem ter, o suporte da visão de mundo compartilhada por todos os falantes e, por consequência, da identidade naquilo que ela tem de mais íntimo e mais comum. (MEJRI, 2017, p. 10, tradução nossa $)^{2}$

Assim, uma Terceira Articulação da Linguagem vem sendo proposta (MEJRI, 1997, 2017), a qual engloba as unidades lexicais que contenham um emprego gramatical próprio. As unidades lexicais da Terceira Articulação da Linguagem são classificadas em dois grupos: a) as unidades monolexicais, formadas de uma única palavra; e b) as unidades polilexicais, conhecidas também como fraseologismos (GONZÁLEZ REY, 2015), formadas de, ao menos, duas palavras, mas que são compreendidas de forma global, como uma única unidade lexical. É o caso, por exemplo, das expressões bom de garfo e olho maior que a barriga, usados para se referir a 'alguém que é guloso'. Os conceitos de monolexicalidade e polilexicalidade são noções desenvolvidas no âmbito dos estudos sobre Fraseologia (Cf. GROSS, 1996; MEJRI, 1997, 2017; SFAR, 2010a, 2010b, 2013; GONZÁLEZ REY, 2015; MONTEIRO-PLANTIN, 2014, 2017; entre outros).

Assim sendo, as unidades fraseológicas são, para além do objeto de análise da Fraseologia, ferramentas que permitem o reconhecimento não apenas da variação linguística existente em uma determinada língua mas também de uma língua para outra (considerando que a construção e o significado dos fraseologismos diferem de acordo com a região/país em que são utilizados), como ainda da mudança linguística, uma vez que tais expressões são, por vezes, formadas de termos antigos que perderam sua definição, sua motivação ou sua ortografia original no falar moderno e que são empregados apenas em uma determinada construção fraseológica, tal como afirma Mejri (2017, p. 12-13):

Em outras expressões, mesmo que as palavras ainda existam na mesma forma em outro lugar

\footnotetext{
${ }^{1} \mathrm{O}$ autor elenca outras possíveis nomenclaturas para as expressões idiomáticas. Entre as mais usuais estão: expressão figée, sequência figée, fraseologismo, unidade fraseológica, expressão figurada, perífrase, forma de falar, provérbio, locução verbal, máxima, ditado etc. (traduções nossas). Neste trabalho tais termos serão empregados de maneira indistinta.

${ }^{2}$ No original: Les expressions idiomatiques soit le pur produit de la dynamique des langues vivantes. Elles sont l'empreinte des différents usages des locuteurs à travers les âges, le lieu de la mémoire des communautés linguistiques, le siège des différentes configurations que les concepts peuvent avoir, le support de la vision du monde partagée par tous les locuteurs, et par conséquent de l'identité dans ce qu'elle a de plus intime et de plus commun.
} 
da língua, elas não são empregadas no sentido atual, mas preservam significados desaparecidos. [...] Enfim, em algumas expressões, encontramos o que poderíamos chamar de "fósseis morfológicos". (tradução nossa) ${ }^{3}$

Isso dito, nas seções que seguem, apresentaremos, de forma condensada, as principais características e definições dos fraseologismos (seção 2), assim como uma proposta de análise de unidades fraseológicas existentes em textos autênticos escritos em língua francesa (seções 3 e 4), tomando como exemplo as narrativas da série francesa de contos infanto-juvenis Le Petit Nicolas, escrita no início da década de 1960 por Goscinny e ilustrada por Sempé (1960-1964).

\section{OS ESTUDOS FRASEOLÓGICOS}

Fraseologismo é o fenômeno da linguagem utilizado como objeto de estudo da Fraseologia. Segundo a fraseóloga brasileira Monteiro-Plantin (2017, p. 1-2), os fraseologismos são caracterizados pela combinação de unidades léxicas, relativamente estáveis, com certo grau de idiomaticidade, formados por duas ou mais palavras, que constituem a competência discursiva dos falantes de uma determinada língua. Os fraseologismos são convencionalmente empregados em contextos precisos, ainda que muitas vezes de forma inconsciente.

\subsection{BREVE HISTÓRIA DA FRASEOLOGIA}

A fraseóloga espanhola Isabel González Rey, professora da Universidade de Santiago de Compostela, em seu livro intitulado La phraséologie du français, destaca que,

em todas as línguas, as primeiras evidências de interesse em expressões fixas [fraseologismos] podem ser encontradas em coleções de provérbios, máximas e outras fórmulas gnômicas, que, ao longo dos séculos, transmitem uma sabedoria popular e universal. Com o tempo, essas obras incorporaram todo tipo de expressão, de locuções, tendo como ponto em comum serem sequências de palavras reproduzidas com frequência que são portadoras de imagens. Quando, no século XIX, apareceu a lexicografia, os dicionários gerais introduziram essas sequências fixas no final dos artigos de cada entrada que forma o cabeçalho (GONZÁLEZ REY, 2015, p. 00) (tradução nossa)

\section{A autora continua:}

A fraseologia, por outro lado, percorrerá um longo caminho antes de alcançar seus direitos, o que todos acabarão the concedendo entre as teorias linguísticas. De fato, depois de começos hesitantes que datam do final do século XIX, ela se manifesta timidamente em obras de linguística geral durante a primeira metade do século XX. Por muito tempo ignorada pelos linguistas, a fraseologia sempre buscou seu lugar como disciplina e foi, aos poucos,

\footnotetext{
${ }^{3}$ No original: Dans d'autres expressions même si les mots existent toujours sous la même forme ailleurs dans la langue, ils ne sont pas employés dans le sens courant mais préserve des significations disparues. [...] Enfin, dans certaines expressions, on trouve ce que l'on pourrait appeler des « fossiles morphologiques ».
} 
sendo incorporada às vezes pela lexicologia, às vezes pela gramática, às vezes pela estilística. (GONZÁLEZ REY, 2015, p. 00) (tradução nossa)

O primeiro teórico a fazer investigações a respeito das unidades fraseológicas, na Europa Ocidental, foi Charles Bally. Ao utilizar, em 1909, o termo fraseologia com o sentido de disciplina científica, Bally considera que uma locução composta se dá quando "em um grupo de palavras, cada unidade gráfica perde uma parte de sua significação individual, ou não conserva nenhuma, a combinação de seus elementos se apresenta com um único sentido" (BALLY, 1909, p. 65-66 apud MONTEIRO-PLANTIN, 2014, p. 26 e 27). Bally foi considerado como o pai da Fraseologia e, como tal, classificou as expressões linguísticas em três grupos ${ }^{4}$ :

(1) a. Combinações livres: associações ocasionais ou agrupamentos passageiros (ex.: ter uma casa);

b. Agrupamentos usuais ou séries fraseológicas (ex.: ter sorte);

c. Unidades fraseológicas (ex.: ter o rei na barriga).

Contudo, embora Bally (1909) tenha feito contribuições importantes para desenvolvimento dos estudos fraseológicos, Monteiro-Plantin (2014) ressalta que

entretanto podemos dizer que as bases teóricas que propiciaram as pesquisas em Fraseologia foram estabelecidas pelos linguistas soviéticos por volta de 1940, com destaque especial para Vinogradov (1947). Foram estes linguistas que estabeleceram os conceitos fundamentais da disciplina. Posteriormente, estas pesquisas foram desenvolvidas nos trabalhos da Europa oriental, principalmente na República Democrática Alemã. (MONTEIRO-PLANTIN, 2014, p. 27)

No Brasil, foi a fraseóloga Ortiz Alvarez, professora da Universidade de Brasília, a responsável pela divulgação dos trabalhos de Vinogradov e Polivanov. Porém, na América Latina, foi graças aos trabalhos de Augusto Zuluaga (1980), de origem colombiana, e das cubanas Zoila Vitória Carneado Moré e Antonia Maria Tristá Perez (1986), que os estudos fraseológicos tiveram impulso inicial.

\subsection{CATEGORIZAÇÃO E CARACTERÍSTICAS DOS FRASEOLOGISMOS}

As unidades fraseológicas podem ser categorizadas em, basicamente, três tipos: a) Colocação: são expressões constituídas, através da coocorrência léxico-sintática, por uma base e um colocado, isto é, por palavras que aparecem juntas com tamanha frequência que sua compreensão é dada sempre em blocos e que, por isso, dão a impressão de que foram constituídas de forma natural (MONTEIRO-PLANTIN, 2017; GROSS, 1996; GONZALEZ REY, 2015); b) Expressão idiomática: "é uma lexia complexa indecomponível, conotativa e cristalizada em um idioma pela tradição cultural"

\footnotetext{
${ }^{4}$ Informações e exemplos extraídos de Monteiro-Plantin (2014, p. 27).
} 
(XATARA, 1998, p. 170); e c) Pragmatemas: remetem às marcas de discurso bem como aos atos de fala, polidez ou impolidez.

Os fraseologismos apresentam características específicas que os definem como tais e que permitem sua identificação, independentemente da língua em que estejam sendo empregados. São cinco as principais características dos fraseologismos, apresentadas a seguir.

\subsubsection{Polilexicalidade}

Os fraseologismos devem estar integrados por, no mínimo, duas palavras (lexias), que são compreendidas de forma global, com sentido único, como sendo uma única unidade lexical (GROSS, 1996). É o caso, por exemplo, das expressões bater as botas, empregada com o sentido de 'morrer', e estar com a pulga atrás da orelha, empregada com o sentido de 'preocupado'.

Contudo, a respeito da polilexicalidade dos fraseologismos, Monteiro-Plantin (2017, p. 8-9) ressalta que, embora todo fraseologismo seja polilexical, nem toda sequência polilexical é uma unidade fraseológica. Os fraseologismos guarda-chuva, guarda-roupa e rádiorelógio, por exemplo, são palavras compostas, cuja formação obedece a regras produtivas (composição, derivação e justaposição), mas não são consideradas como fraseologismos.

\subsubsection{Fixação (ou cristalização)}

A fixação é uma característica que diz respeito à impossibilidade/restrição de mobilidade das lexias que compõem os fraseologismos e à possibilidade de substituições/alterações tanto no eixo sintagmático quanto no eixo paradigmático. A fixação é compreendida em diferentes níveis: o nível formal e o nível semântico (GONZÁLEZ REY, 2015).

No nível formal, considera-se que há uma soldadura entre as palavras que integram o fraseologismo e que, portanto, impossibilita a mudança de um dos elementos por outro, semelhante ou não, a risco de perda do sentido global da unidade. Por exemplo, no fraseologismo bater as botas ('morrer'), ao trocar o elemento botas por outro do mesmo campo semântico (como, por exemplo, bater as sandálias ou bater os sapatos), a possibilidade de recuperação do sentido de 'morrer' se perde e, assim, o fraseologismo deixa de existir.

No nível semântico, considera-se o sentido global que o fraseologismo apresenta. O significado não resulta da soma dos itens lexicais, mas sim de sua totalidade. Em cair a ficha, por exemplo, a combinação livre das lexias, ou seja, seu sentido literal, remete aos telefones públicos, existentes no Brasil durante as décadas de 1980 e 1990, que funcionavam à base de fichas telefônicas. Nesse maquinário, quando a ligação telefônica era completada, a ficha caía. Entretanto, ao considerar a expressão cair a ficha de maneira fixa, ou cristalizada, com o sentido único de 'entender', trata-se, portanto, de um fraseologismo, graças ao sentido global, motivado pela relação metafórica da ligação telefônica com o verbo 'entender'. 


\subsubsection{Frequência ou convencionalidade}

As características de frequência de uso e de convencionalidade de um determinado fraseologismo estão intimamente ligadas, visto que "um fraseologismo pode ter se tornado convencional devido a sua frequência de uso, ou pode ser frequente por ser o mais convencional" (MONTEIRO-PLANTIN, 2014, p. 10).

A característica da frequência trata da recorrência de uma combinação formativa do fraseologismo que é repetida quase sempre na mesma ordem (GONZÁLEZ REY, 2015). O fraseologismo estupidamente gelado é um bom exemplo para esta característica. Devido ao grande uso do intensificador 'estupidamente', atrelado ao adjetivo 'gelado', convencionalizou-se o seu uso.

\subsubsection{Desautomatização lexical (ou défigement)}

A desautomatização lexical ou défigement (do francês des - fixação) é a manipulação da forma ou do sentido de um fraseologismo com o intuito de produzir efeitos de sentido. Tal manipulação é comumente empregada em títulos de artigos jornalísticos e slogans publicitários. Em outras palavras, trata-se dos jogos de palavras realizados a partir das expressões fixas (GROSS, 1996). O fraseologismo Deus é brasileiro pode gerar, a título de exemplificação, a desautomatização Adeus é brasileiro, publicado pelo jornal esportivo português $A$ Bola como uma maneira satírica de anunciar a eliminação da Seleção Brasileira de Futebol da Copa Mundial de 2014, como se vê na Figura ${ }^{5}$ 1, a seguir.

\footnotetext{
5 A imagem encontra-se disponível em: https://www.terra.com.br/esportes/brasil/pelo-mundo-jornaisdestacam-humilhacao-do-brasil-confira,f8499a6d3ba17410VgnVCM10000098cceb0aRCRD.html. Acesso em: 28 jan. 2019.
} 


\section{Revista

Figura 1: Capa do jornal esportivo $A$ Bola, de 9 de julho de 2014

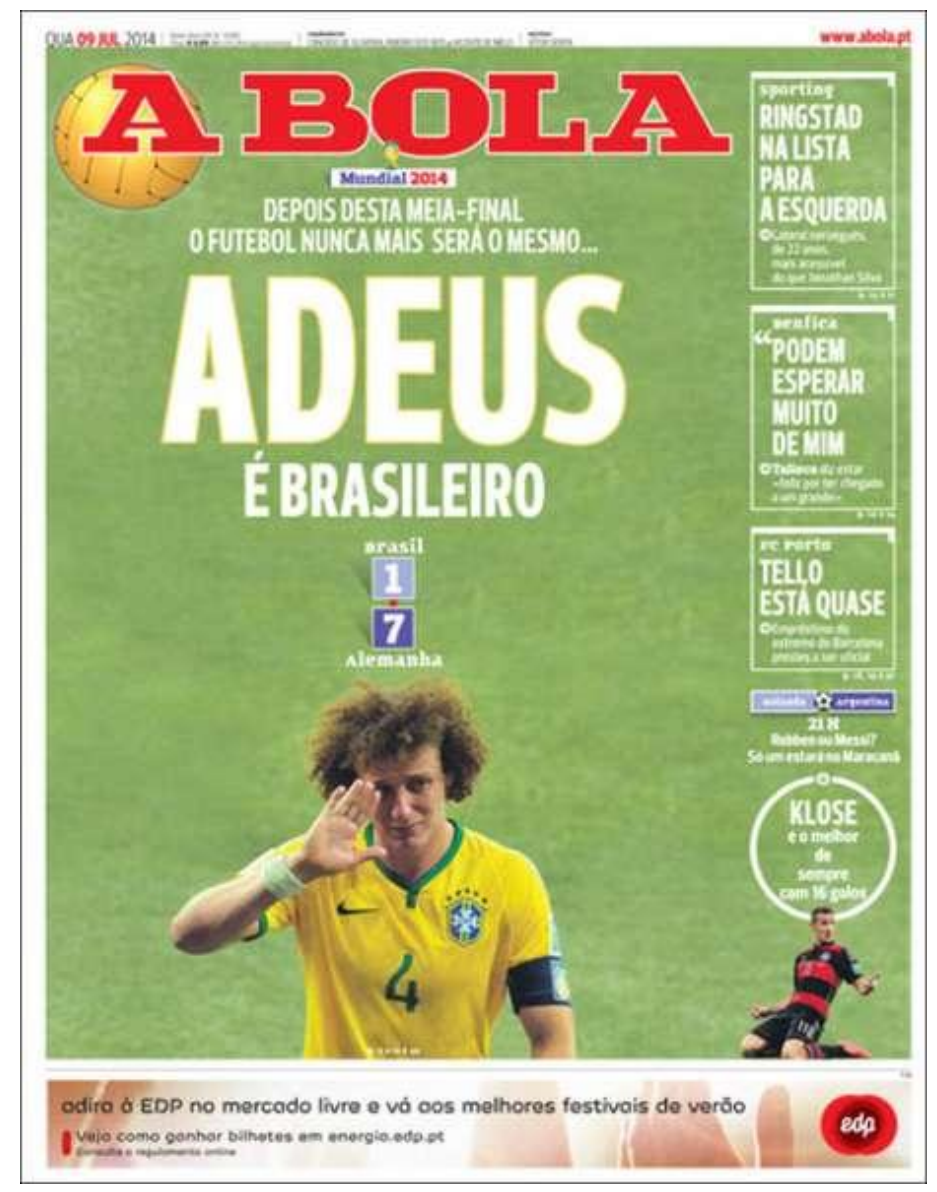

\subsubsection{Idiomaticidade}

A característica da idiomaticidade está ligada às noções de transparência e opacidade semânticas:

Dizemos que uma expressão é idiomática apenas quando seu significado não é transparente, isto é, quando o significado da expressão toda não corresponde à somatória do significado de cada um de seus elementos. [...] É preciso que essa noção fique clara porque, em português, idiomático é usualmente empregado com o sentido de "referente a ou próprio de um idioma". (TAGNIN, 2013, p. 22) (grifos da autora)

Em fraseologia, o termo idiomático é reservado para significar 'não transparente' ou 'opaco'. Segundo essas noções, os fraseologismos podem ser compreendidos de duas maneiras: a) expressões semanticamente transparentes; e b) expressões semanticamente opacas. As expressões transparentes são aquelas em que as unidades lexicais que as compõem têm significados ordinários, de fácil compreensão no falar corrente. Por outro 
lado, o significado das expressões opacas não está diretamente ligado à definição de cada palavra, mas, ao contrário, ao conceito idiomático contido na transmissão cultural desta expressão (MEJRI, 1997, 2017).

Nos fraseologismos João está nadando em dinheiro e Sua batata está assando, por exemplo, o sentido do primeiro pode ser facilmente compreendido por um falante do português do Brasil, seja ele nativo ou não. Mesmo que sua definição seja metafórica, para declarar que João é um homem rico, sua composição é transparente. Contudo o mesmo não acontece no segundo exemplo, que não faz referência a legumes que estejam literalmente no forno, mas funciona como um alerta a alguém que tenha feito algo de errado e que as consequências de seus atos estão por vir.

\section{OS FRASEOLOGISMOS EM TEXTOS AUTÊNTICOS}

Entende-se por textos autênticos aqueles que não foram escritos para fins pedagógicos, mas para servir a uma comunidade nativa da língua, embora possam ser utilizados em sala de aula de línguas estrangeiras, como é o caso, em língua francesa, dos contos da série infanto-juvenil Le Petit Nicolas (GOSCINNY; SEMPÉ, 1960-1964), comumente lida de forma paradidática durante as aulas de FLE (Francês Língua Estrangeira), quer por recomendação do livro didático (cf. CAPELLE; MENAND, 2009), quer por indicação de sites especializados em materiais didatizados de FLE. Os contos são narrados em primeira pessoa por uma criança de oito anos, Nicolas, de modo que as narrativas são repletas de fraseologismos, comuns do registro oral de língua francesa.

Em trabalho anterior (SAMPAIO; RIBEIRO, 2018) ${ }^{6}$, percebemos que, embora as expressões idiomáticas tenham ganhado alguma atenção dos dicionários bilíngues e/ou especializados difundidos no Brasil, as colocações e os pragmatemas, como se vê em exemplos como appareil photo, coup de sifflet, prendre une photo, ce n'est pas grave, tout d'un coup, não estão contempladas em tais obras lexicográficas. Essas unidades fraseológicas são pouco observadas, o que, possivelmente, aumenta a complexidade da leitura e compreensão de textos autênticos.

O presente trabalho, que tem como ponto de partida a pesquisa de doutorado de um dos autores, tem como objetivo fazer uma testagem da metodologia desenhada para a coleta e análise dos dados, de modo a verificar e eleger a metodologia que será empregada na tese. Assim, foram verificados os dez primeiros contos do volume 1 da série Le Petit Nicolas (GOSCINNY; SEMPÉ, 1960). Os tipos de fraseologismos procurados foram expressões idiomáticas, colocações e pragmatemas. Foi encontrado um total de 335 unidades fraseológicas, classificados como mostra o Gráfico 1, a seguir.

\footnotetext{
6 Trabalho apresentado como comunicação oral no evento científico I Seminário de Estudos de Linguagem SELING. Organizado e realizado na Universidade Estadual da Bahia (UNEB).
} 


\section{das Letras}

Gráfico 1: Tipos de fraseologismos encontrados nos 10 primeiros contos do volume 1 da série Le Petit Nicolas (SAMPAIO; RIBEIRO, 2018)

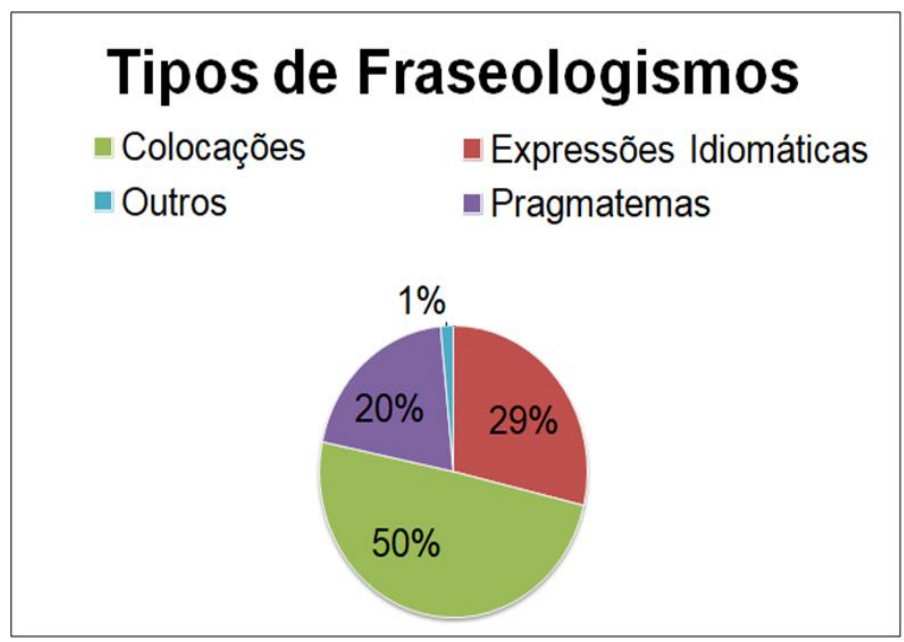

Tal como está exposto no Gráfico 1, a maioria dos fraseologismos encontrados foi classificada como colocações, totalizando 50\% dos dados. Em segundo lugar, encontramse as expressões idiomáticas, com $29 \%$ dos dados. Com $20 \%$, estão os pragmatemas, em terceira posição. As unidades fraseológicas, que ainda não foram possíveis de ser classificadas, foram catalogadas como outros e totalizaram $1 \%$ dos dados encontrados.

$\mathrm{Na}$ categoria outros, encontram-se os xingamentos e truncamentos, exemplificados em (2), a seguir:

(2) a. Il s'en irait (en aller);

b. Le Bouillon;

c. Espèce de guignol / Sale menteur / Vilain cafard.

O exemplo em (2a) apresenta os verbos construídos com o pronome en. Em língua francesa, o pronome en, quando empregado com determinados verbos, pode modificar seu sentido: aller ('ir') / en aller ('ir embora'/'partir'), vouloir ('querer') / en vouloir ('querer mal a alguém') etc.

$\mathrm{O}$ exemplo em (2b) concerne à maneira como Nicolas e seus colegas de classe chamam, de forma zombeteira, o inspetor da escola. Nos contos, Le Bouillon ('o caldo') faz referência ao formato esbugalhado que os olhos do inspetor assumem quando ele reclama com os alunos. Desse modo, não há nenhuma relação aparente com o termo e o apelido criado por Nicolas e seus colegas para o inspetor. Entretanto acreditamos que seja um truncamento da expressão les yeux du bouillon ('os olhos do caldo'), a qual faz alusão às manchas, normalmente em rodelas, de gordura que ficam na superfície dos caldos e sopas, como o caldo de galinha, por exemplo, e que lembram, para as crianças como Nicolas, os olhos do inspetor. 


\section{das Letras}

Nas expressões expostas em (2c) as palavras guignol ('palhaço'), menteur ('mentiroso') e cafard ('barata') são empregadas por Nicolas como xingamentos. Ocorre que, em língua francesa, os termos espèce ('espécie'), sale ('sujo') e vilain ('desagradável') funcionam como intensificadores de xingamentos, sejam eles quais forem. Tais termos são empregados de forma associada aos xingamentos com tamanha frequência que, por vezes, é difícil separálos.

Dessa forma, acreditamos que, devido à frequência da ocorrência dos exemplos apresentados em (2), e apesar do caráter idiossincrático de algumas, essas expressões foram convencionalizadas e, portanto, podem ser consideradas como fraseologismos, ainda que, por hora, não saibamos classificá-las.

\section{ANÁLISE DAS ESTRUTURAS INTERNAS}

Após a classificação dos diferentes tipos de fraseologismos, buscamos verificar a categorização gramatical das unidades fraseológicas, tal como mostra o Gráfico 2, a seguir.

Gráfico 2: Classificação da categoria gramatical dos fraseologismos encontrados nos 10 primeiros contos do volume 1 da série Le Petit Nicolas (SAMPAIO, 2018)

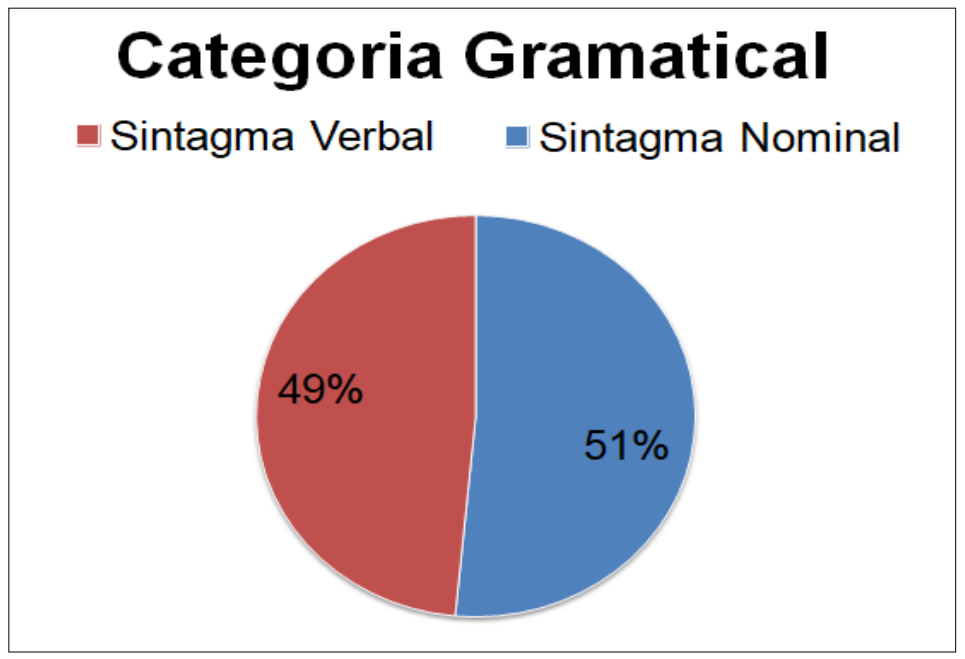

Como é possível observar no Gráfico 2, os fraseologismos que compuseram o corpus deste estudo foram distribuídos em duas categorias: a) sintagmas verbais; e b) sintagmas nominais. Os resultados obtidos foram muito próximos, isto é, 49\% dos dados são classificados como sintagmas verbais, enquanto que 51\% são sintagmas nominais.

Em (3), estão exemplificados alguns fraseologismos compostos por sintagmas verbais e nominais encontrados no corpus:

(3) a. Connaître par coeur (expressão idiomática);

b. Il faut dire que (pragmatema);

c. Montrer du doigt (colocação); 
d. À droite et à gauche (expressão idiomática);

e. Tout d'un coup (pragmatema);

f. Gros mot (colocação).

Os exemplos apresentados entre (3a) e (3c) pertencem à categoria dos sintagmas verbais, ao passo que os fraseologismos expostos entre (3d) e (3f) são referentes aos sintagmas nominais.

Em (3a), trata-se de uma expressão idiomática que, se traduzida literalmente, equivale em português a 'conhecer pelo coração'. Contudo, em termos pragmáticos, o significado atribuído para essa expressão é o de 'memorizar'. Embora o coração não seja frequentemente associado à inteligência, na antiguidade, para os gregos, esse órgão era a sede da coragem, da sensibilidade, da afetividade e da inteligência ${ }^{7}$. Acreditamos que essa seja a motivação da criação do fraseologismo. O fraseologismo presente em (3b) é um pragmatema que, em língua portuguesa, equivale a 'é preciso dizer' e é utilizado como marcador de discurso. Em (3c), a unidade fraseológica é formada por uma base, montrer de ('mostrar a partir de') e um colocado, le doigt ('o dedo'), formando, assim, uma colocação que pode ser traduzida como 'apontar'.

A expressão idiomática presente em (3d), traduzida literalmente como 'à direita e à esquerda', ao ser empregada de forma contextualizada, tem o mesmo sentido que a expressão idiomática de língua portuguesa a torto e a direito, isto é, algo que é feito ou distribuído 'de maneira desorganizada, aleatória'. O pragmatema em (3e), se traduzido ao pé da letra, equivale a 'todo de um golpe'. Contudo é utilizado com o sentido de 'subitamente' ou 'repentinamente'. Por fim, em (3f), a colocação composta pela base gros ('grosso'/'gordo') e o colocado mot ('palavra'), corresponde ao termo 'palavrão', em português.

\subsection{OS SINTAGMAS VERBAIS}

Tendo verificado a categorização gramatical das unidades fraseológicas, buscamos quantificar a aparição dos diferentes tipos de fraseologismos dentro de cada categoria. $\mathrm{O}$ Gráfico 3, adiante, expõe os resultados obtidos para a categoria Sintagma Verbal.

\footnotetext{
${ }^{7}$ Informações extraídas do dicionário online de expressões idiomáticas em língua francesa. Disponível em: http://www.expressio.fr/expressions/par-coeur.php. Acesso em: 28 jan. 2019.
} 


\section{Revista

Gráfico 3: Classificação dos tipos de fraseologismos presentes na categoria Sintagma Verbal (SAMPAIO; RIBEIRO, 2018)

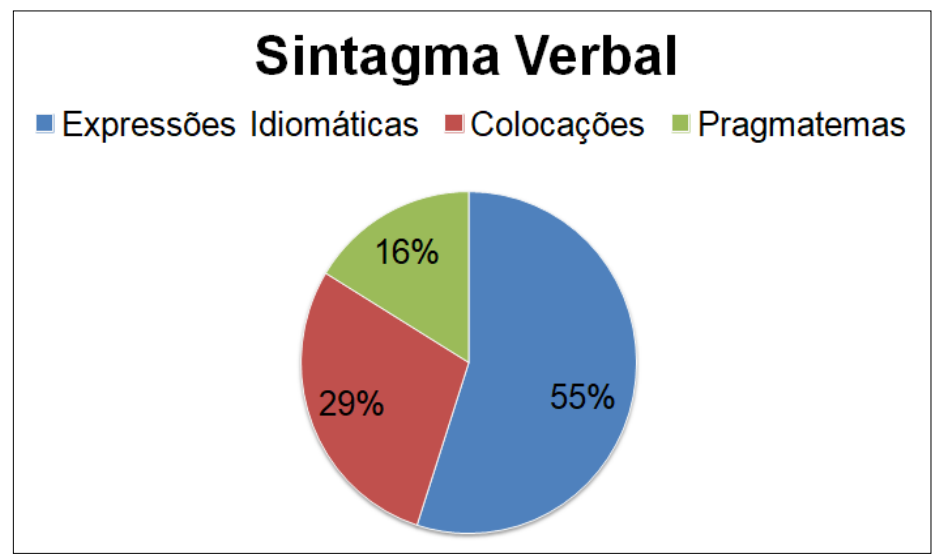

A classificação dos tipos de fraseologismos presentes na categoria Sintagma Verbal ficou assim definida: a maior quantidade é de expressões idiomáticas que computaram $55 \%$ dos dados encontrados. Em segundo lugar, encontram-se as colocações, com 29\% dos dados. Por último, estão os pragmatemas, com 16\%.

Para verificar a recorrência da estrutura interna dos sintagmas verbais, consideramos apenas as estruturas com cinco ou mais ocorrências, exibidas em (4), a seguir.

(4) a. Verbo + Determinante + Nome (62 ocorrências);

b. Verbo + Det. + Nome + Prep. + Det. + Nome (18 ocorrências);

c. Verbo + Nome (10 ocorrências);

d. Pronome + Verbo + Nome (7 ocorrências);

e. Pronome + Verbo + Verbo (5 ocorrências).

Em (5) e (6), à frente, estão exemplificados fraseologismos compostos pelas estruturas internas mais recorrentes entre os sintagmas verbais, isto é, as estruturas presentes em (4a) e (4b).

(5) a. Avoir l'air;

b. Faire la tête;

c. Faire le guignol;

d. Prendre une photo.

A estrutura interna apresentada em (4a), e exemplificada em (5), é não apenas a de maior frequência como também aquela que retrata a maior diversidade de expressões. Embora o verbo faire ('fazer'), por exemplo, presente nas expressões em (5b) e (5c), seja um dos mais usuais na construção de expressões idiomáticas de língua francesa, podemos 
encontrar fraseologismos com a mesma estrutura interna que, contudo, empregam outros verbos como em (5a), com o verbo avoir ('ter'), e em (5d), com o verbo prendre ('pegar/tomar'). O mesmo não acontece em (6), como é possível se observar a seguir:

(6) a. Être le chouchou de la maitresse;

b. Etre le premier de la classe;

c. Etre le dernier de la classe;

d. Avoir une boule dans la gorge.

Apesar de ser a segunda estrutura interna mais recorrente entre os sintagmas verbais, estas expressões, como fica evidenciado a partir de (6), são as mesmas, que se repetem ao longo dos textos, visto que são expressões frequentes no contexto escolar e, portanto, fazem parte do cotidiano do personagem narrador, Nicolas. A única exceção a tal repetição está em (6d), com apenas duas ocorrências ao longo dos dez contos, contra dezesseis ocorrências das demais expressões.

\subsection{OS SINTAGMAS NOMINAIS}

Assim como foi feito com os resultados obtidos na categoria Sintagma Verbal, quantificamos a frequência dos diferentes tipos de fraseologismos compostos por Sintagmas Nominais, tal como exposto no Gráfico 4:

Gráfico 3: Classificação dos tipos de fraseologismos presentes na categoria Sintagma Nominal (SAMPAIO; RIBEIRO, 2018)

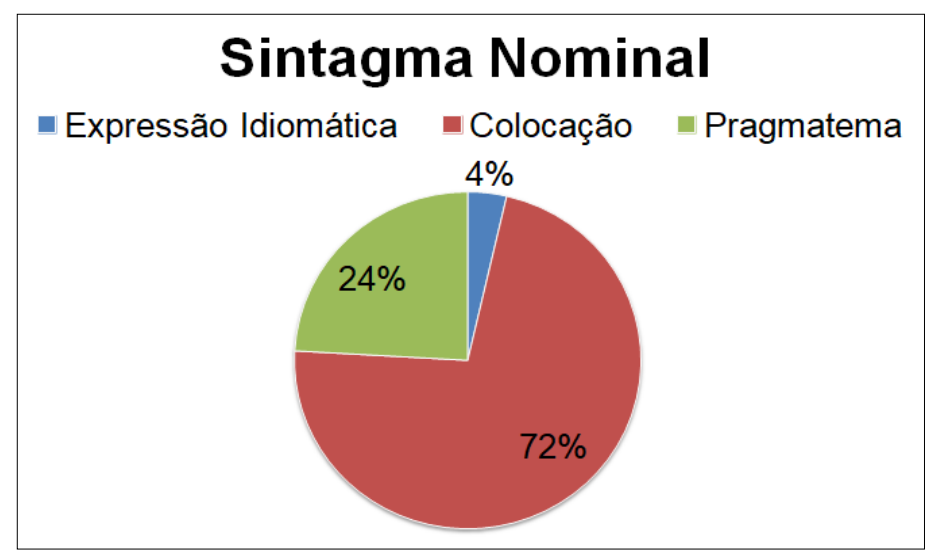

Os tipos de fraseologismos presentes na categoria Sintagma Nominal foram computados da seguinte forma: com quase três quartos do total dos dados, $72 \%$, ficaram as colocações, representando a maior quantidade de fraseologismos presentes nessa categoria. Em segundo plano, estão os pragmatemas, com $24 \%$ dos dados. Com apenas 4\% e, portanto, em última posição, estão as expressões idiomáticas. 
Do mesmo modo que ocorreu com os Sintagmas Verbais, também verificamos a recorrência da estrutura interna dos Sintagmas Nominais. De igual forma, consideramos apenas as estruturas com cinco ocorrências ou mais, exibidas em (7).

(7) a. Nome + Prep. + Nome (61 ocorrências);

b. Determinante + Determinante + Nome (18 ocorrências);

c. Adjetivo + Nome (17 ocorrências);

d. Advérbio + Adjetivo (9 ocorrências);

e. Nome + Prep. + Det. + Nome (8 ocorrências);

f. Advérbio + Preposição + Nome (6 ocorrências);

g. Conjunção + Demonstrativo (6 ocorrências);

h. Advérbio + Advérbio (5 ocorrências);

i. Nome + Adjetivo (5 ocorrências).

As estruturas internas que têm maior frequência entre os sintagmas nominais, expostas em (7a) e (7b), estão exemplificadas adiante, em (8):

(8) a. Arbitre de touche;

b. Coup de poing;

c. Espèce de guignol.

Os fraseologismos presentes em (8), como está evidenciado, representam colocações que seguem o mesmo padrão da estrutura interna apresentada em (7a). A colocação em (8a), formada pela base arbitre de ('árbitro') e o colocado touche ('toque'), pode ser, assim, traduzida em português como 'árbitro de toque'. Porém seu significado corresponde a 'bandeirinha', juiz assistente de partidas de futebol encarregado de acenar com uma pequena bandeira ao observar uma infração das regras do jogo. Em (8b), a colocação é formada pela base coup de ('golpe de') e o colocado poing ('punho') e o sentido empregado para essa colocação é de 'soco'/'murro'. A colocação em (8c), como vimos anteriormente, é um insulto.

As unidades fraseológicas concebidas pela estrutura interna presente em (7b) estão expostas em (9):

(9) a. Tout le monde;

b. Tout le temps.

Assim como evidenciamos na composição dos fraseologismos com a estrutura interna de segunda maior recorrência dos sintagmas verbais, a frequência das unidades fraseológicas apresentadas em (9) caracteriza um constante reaparecimento das mesmas colocações ao longo dos contos, comprovando, desse modo, a existência de uma convencionalidade.

Salientamos que, no que tange à exemplificação dos fraseologismos compostos pelas estruturas internas mais amiúdes, tanto entre os sintagmas verbais quanto os 
nominais, optamos por trazer apenas aqueles que representavam as duas estruturas internas mais frequentes de cada categoria, visto que nossa intenção era a de fazer uma amostragem dos dados já coletados no âmbito da pesquisa de doutorado de um dos autores.

\section{CONSIDERAÇÕES FINAIS}

Ao nos debruçarmos sobre os dados, percebemos que a estrutura interna mais frequente entre os Sintagmas Verbais é Verbo + Determinante + Nome, enquanto que a estrutura interna mais recorrente entre os Sintagmas Nominais é Nome + Preposição + Nome. Assim, observamos que as estruturas internas mais constantes entre os sintagmas verbais e os sintagmas nominais são curtas e, portanto, de fácil assimilação para um falante nativo de português do Brasil. Tal observação nos leva a crer que a estrutura sintática dos fraseologismos encontrados nos dez primeiros contos do volume 1 da série Le Petit Nicolas não causa grande dificuldade de compreensão para um leitor brasileiro de francês. É possível que essa dificuldade esteja ligada a fatores semânticos, os quais deverão ser verificados futuramente.

Por fim, ressaltamos que a pequena amostra de análise das unidades fraseológicas aqui exposta não tem um caráter definitivo. Nossa intenção foi verificar o funcionamento interno dos fraseologismos utilizados em língua francesa no início da década de 1960 e, a partir daí, abrir portas para novas investigações.

\section{REFERÊNCIAS}

BALLY, Charles. Traité de stylistique française. v. 2. Paris: Klincksieck, 1909.

CAPELLE, G.; MENAND, R. Le nouveau taxi! 2. Méthode de français. Paris: Hachette Livre, 2009.

CARDOSO, Suzana Alice. Geolinguistica: tradição e modernidade. São Paulo: Parábola Editorial, 2010.

CHAMBERS, J. K.; TRUDGILL, Peter. La dialectología. Madrid: Visor Libros, 1994.

DUBOIS, Jean. et al. Dicionário de linguística. São Paulo: Cultrix, 2014.

FERREIRA, Carlota; CARDOSO, Suzana Alice. A dialetologia no Brasil. São Paulo: Contexto, 1994.

GONZÁLEZ REY, M. I. La phraséologie du français. Toulouse: Presses Universitaires du Midi, 2015.

GOSCINNY, R; SEMPÉ, J-J. Le Petit Nicolas. Paris: Denoël, 1960. . Les récrés du Petit Nicolas. Paris: Denoël, 1961. . Les vacances du Petit Nicolas. Paris: Denoël, 1962. . Le Petit Nicolas et les copains. Paris: Denoël, 1963. . Le Petit Nicolas a des ennuis. Paris: Denoël, 1964.

GROSS, Gaston. Les expressions figées en français : noms composés et autres locutions. Paris: Ophrys, 1996.

LEITE, Y.; CALLOU, D. M. I. Como falam os brasileiros. $3^{\text {a }}$ ed. Rio de Janeiro: Zahar, 2006. 
MARTINET, André. Elementos de linguística geral. $8^{a}$ ed. São Paulo: Martins Fontes, 1978. MEJRI, Salah. Le figement lexical : descriptions linguistiques et structuration sémantique. Tunis : Faculté des lettres de la Manouba, 1997. . Les expressions idiomatiques. v. 1. Paris: Éditions Garnier, 2017.

MONTEIRO-PLANTIN, R. S. Fraseologia - era uma vez um patinho feio no ensino de língua materna. $1^{a}$ ed. Fortaleza: Imprensa Universitária, 2014.

. Fraseologia e paremiologia: para que ensinar, se todo o mundo sabe? Revista Virtual de Estudos da Linguagem, v. 15, p. 1-16, 2017.

SAUSSURE, Ferdinand de; BALLY, Charles; SECHEHAYE, Albert. Curso de lingüistica geral. $7^{a}$ ed. São Paulo: Cultrix, 1975.

SFAR, Inès. Figement et incorporation: l'établissement d'un concordancier bilingue (français-arabe). Meta, v. 55, n. 1, Montréal, p. 158-167, 2010.

. L'analyse prédicative : un outil pour l'évaluation de la traduction des textes bilingues alignés. Synergies, n. 2, Tunis, p. 99-113, 2010.

- Les collocations dans le discours spécialisés: le cas de la terminologie ornithologique. Language Design, n. 14, Espanha, p. 19-38, 2013.

TAGNIN, Stella. O jeito que a gente diæ: expressões idiomáticas e convencionais - inglês e português. São Paulo: Disal, 2005.

TRISTA PEREZ, A. M.; CARDENADO MORE, Z. Elementos somáticos en las unidades fraseológicas. Annuario L/L, n. 17, p. 55-68, 1986.

XATARA, Cláudia. Tipologia das expressões idiomáticas. Alfa - Revista de Lingüística, v. 42, São Paulo, p. 169-176, 1998.

ZULUAGA OSPINA, A. Introducción al estudio de las expresiones fijas. Studia Romancia, n. 10, Frankfurt/Berna, Peter Lang, 1980. 